\title{
Survey of Reproductive Health Information Seeking Behaviour among Pregnant Women in Some Selected Hospitals in Kano Metropolis, Nigeria
}

\author{
Hadiza Mustapha Namadi* and Aondover Eric Msughter \\ Department of Mass Communication, Bayero University, Kano, Nigeria \\ *Corresponding author: Hadiza Mustapha Namadi, Hadiza Mustapha Namadi, Department of Mass Communication, \\ Bayero University, Nigeria
}

\section{ARTICLE INFO}

Received: 幽 September 21, 2020

Published: 幽 September 29, 2020

Citation: Hadiza Mustapha Namadi, Aondover Eric Msughter. Survey of Reproductive Health Information Seeking Behaviour among Pregnant Women in Some Selected Hospitals in Kano Metropolis, Nigeria. Biomed J Sci \& Tech Res 30(5)-2020. BJSTR. MS.ID.005006.

\begin{abstract}
Reproductive health information among pregnant women is a global concern because it deals with maternal health. The growing interest in maternal health is reflected in the Sustainable Development Goals (SDGs) programs. Furthermore, the increasing attention given to reproductive health information globally has been concentrated on the reduction of maternal mortality. This study investigated the reproductive health information seeking behaviour among pregnant women in some selected hospitals in Kano Metropolis. Positivist approach of data generation and analysis was adopted as the study design. 215 respondents across 9 hospitals in Kano Metropolis was the sample of the study. Survey method was used and data was collected by using questionnaire. Convenient sampling technique was used in the study. Health Belief Model and Wilson Model were used to help in discussing the findings of the study. The result revealed that majority (48.8\%) of the respondents attended antenatal services very early. Similarly, majority (47.9\%) got information about antenatal activity from clinic while $26 \%$ sourced it from mass media and strongly agreed that the information was very useful. The study concluded that reproductive health information obtained by the pregnant women is very useful and relevant and able to meet their information needs as pregnant women, the information they received made their pregnancy life easier and understandable to the changes occurring in their body. A comparative study on reproductive health information attitude between rural and urban pregnant women should therefore be conducted as recommended in the study.
\end{abstract}

\section{Introduction}

Health professionals and health workers target different categories of people using sources of information including the mass media of communication. McQuail [1] describes mass media as the organized means for communicating openly and at a distance to many receivers within a short space of time. Radio as one of the mass media, is one of the cheapest medium, which is used to transfer information to target audiences especially in the developing nations, such as Nigeria. State owned-radio station presents news and information, using local language, which make it easier for the people in that locality to understand the message presented to them, that is why health professionals and health workers use radio as one of their media in which they enlighten the public especially women on its activities. These programs are mostly sponsored by organizations like World Health Organizations
(WHO), United Nation International Children Emergency Fund (UNICEF) or non- governmental organizations like Maternal and Neonatal Child Health 2 (MNCH2), among others. These programs mostly target women and children due to the fact that they are more vulnerable when it comes to the issue of health, therefore information on reproductive health is provided to them.

Information is a major resource that is needed in every sphere of life endeavour especially in health matters. Information assist in reducing the degree of uncertainty and ignorance in the operating environment, therefore the quality of information a pregnant women receives enhances her rightful choice of health care on reproductive health. Pregnancy is a period of substantial physical and role change for women, which is also a time when health related behaviours are more salient because they affect 
the pregnant mother as well as the developing fetus [2]. Getting information during pregnancy can improve the health knowledge of the expectant mother [3]. Substantial information can help pregnant women to communicate with health service providers, demonstrate preventive health care behaviours, and improve selfcare abilities. The information provides them with the opportunity to learn about their pregnancy, childbirth, parenting, and in case of any potential health problem, will be diagnosed and treated at early stage. For pregnant women to adequately live a healthy life and ensure the safe delivery of their babies, they need to search and acquire information necessary for healthy living.

The search for information, however, starts with the identification of a gap in knowledge for which the individual makes an effort to bridge. According to [4] information need occurs whenever an individual's knowledge fails. Saleh [5] states that the most paramount health information required is antenatal and postnatal care, how to safely deliver pregnancy and immunizations especially on the six childhood killer disease, which are polio, whooping cough, tetanus, diphtheria, measles, and tuberculosis. Wilson [6] notes that in the course of seeking information, an individual may interact with manual information in the form of newspaper or a library or with computer based systems, such as web. Information can be derived from a variety of sources, including books, journals, the internet, family or relatives, and persons at the work place (Doctors or paramedical staff in antenatal clinics for pregnant women). UNICEF [7] observed that in the poorest parts of the world, the risk of a women dying as a result of pregnancy or childbirth during her lifetime is about one in six compared to about one in 30,000 in Northern Europe. India being a developing country contributes $26 \%$ of the global burden of maternal deaths with nearly 136,000 women dying annually due to causes related to pregnancy and childbirth. Udofia, et al. [8] observed that Africa accounts for the highest burden of mortality among women and children in the world. Oyedele [9] affirms that Nigeria ranks high among the list of countries with high maternal and infant mortality rates with a ratio of 545 per 100,000 live births on the maternal mortality index, therefore, such revelation makes it necessary to study the reproductive health information seeking behaviour among pregnant women as this will create more awareness of maternal health care issues.

Poor reproductive health is one of the barriers to development, affecting the health status of humans in the developing world, women are the most vulnerable groups to the consequences of poor reproductive health, and they face many reproductive health threats including pregnancy complication, sexually transmitted infection (STIs) and HIV/AIDS. Reproductive Health encompasses a wide range of events and conditions, which take place throughout the life span. Globally, more than half a million women die of complications due to pregnancy, child birth and postpartum period annually. Kistiana [10] noted that about 99 percent $(533,000)$ of these deaths occur in developing regions, with sub-Saharan Africa and Southern Asia accounting for 86 percent of maternal deaths. In sub-Saharan Africa, it is estimated that 30 women die from complications of pregnancy and childbirth every hour of each day [11] . In other words, about 270,000 maternal deaths occur every year. Furthermore, the lifetime risk of maternal mortality in Africa is 1 in 26 [12]. About 125,000 women and 870,000 newborn babies on the continent die annually in the first week after delivery [13], and more than two thirds of maternal deaths occur after delivery. Warren, et al. [13] found that 30 to 50 maternal morbidities occur for each maternal death.

The World Bank's estimate of 630 per 100,000 maternal mortality ratio suggests that the maternal health situation for women in Nigeria is quite poor [14]. With an estimated 59,000 maternal deaths annually, Nigeria contributes 10 percent of the world's maternal deaths [15]. Metiboba [16] noted that 1 in 80 women in Nigeria die as a result of pregnancy-related complications. Some hospital based studies in Nigeria revealed disparities in maternal mortality rates across the country. Among 2,728 deliveries in a teaching hospital, in Sagamu, Southwest Nigeria 75 maternal deaths occurred between 2000 and 2005. 267 maternal deaths occurred among 38,768 deliveries in the Jos teaching hospital (North central), between 1985 and 2001, 60 maternal deaths occurred between 2004 and 2008 in Enugu state teaching hospital, South east Nigeria [17]. The situation is even more critical in Northern Nigeria, where strong cultural and religious beliefs and practices involving childbirth contribute significantly to maternal morbidity and mortality. Scholars like $[10,18]$ have linked the high maternal mortality ratios to the inaccessibility of health services, lack of functional and effective health care systems, and more importantly, the non-use of modern maternal health care services, such as antenatal care, delivery care and postnatal care, that is why reproductive health information should be provided to pregnant women in order to reduce the number of deaths to occur, therefore, within this context, the study is conducted in order to survey the reproductive health information seeking behaviour among pregnant women going for antenatal in some selected hospitals in Kano Metropolis.

\section{Problem Statement}

Jiyane [19] observed that a number of factors create problems when accessing information by any community, especially in the peri-urban community. He articulated that most information and access is from the media, such as radio, television, books, magazine, posters, health centers, community groups and clubs. However, illiteracy, poverty, unemployment and poor infrastructure, hinder rural community to access information in the peri-urban communities. The findings of the research also revealed that during antenatal care, some women prefer having access to modern technology, such as ultrasound scans so as to enable pregnancy more positive, which will guarantee the baby's live in the womb. 
Infertility on the other hand is found both in men and women but it is a particular burden in women. Such pressure to reproduce is intense in agrarian societies, which have a high demand for labour. Just as beliefs and practices regarding fertility and culturally patterned, birth itself is a cultural production as noted by [20]. Gazali, et al. [21] identified low self-esteem and socio-demographic factors as among the problems faced by women when seeking information.

They state that there are many challenges women face in order to access health and maternity information. The social and economic status is another contributing factor in this country where poverty levels have increased in previous years, also the physical access, cost and lack of ability to use information and illiteracy, has made it impossible for illiterate women especially having easy access to information relating to women's health and maternity issues. A study conducted by [22] revealed that the barriers to accessing information include the use of medical terminology by the information source, which the information seeker may not understand. Furthermore, [23] also affirm that low levels of literacy and the understanding of medical information constitute to the barriers of health information seeking. Going by the preceding observation, there is a lacuna in the literature regarding reproductive health information seeking behaviour among pregnant women in Kano Metropolis, which the current study is conceived.

\section{The Basic Tools of Scientific Inquires}

Based on the problem statement, the following research questions are set:

1. What are the sources of reproductive health information used by pregnant women in Kano metropolis?

2. How useful were the sources of maternal information to pregnant woman in Kano metropolis?

3. How early do pregnant women attend antenatal clinics?

4. What are the outcomes of antenatal information seeking behaviour among pregnant women in Kano metropolis?

\section{Operational Definitions of Terms}

Antenatal Care: This refers to health care during pregnancy provided by primary healthcare centers and it is synonymous with prenatal and concerned with the care and treatment of the unborn child and of pregnant women in Kano metropolis.

Health: Is a state of complete physical, mental and social wellbeing on reproductive health among pregnant women in Kano metropolis.

Information Needs: This is the recognition that proves one's knowledge to be inadequate to satisfy a goal and foundation of information seeks for reproductive health among pregnant women in Kano metropolis.
Information Seeking: this refers to the psychological or mental ability for women to perceive current state of possessed knowledge about reproductive health information among pregnant women in Kano metropolis.

Information Seeking Behaviour: is a process that begins with the challenges and problems that compel the information seeker to look for information regarding reproductive health among pregnant women in Kano metropolis.

Reproductive Health: it entails the mental and social wellbeing as well as the absence of disease or sickness, in all matters relating to the reproductive system, its functions and processes among pregnant women in Kano metropolis.

Women: An Adult female, human belonging to a specified occupation, group, nationality, or other category in relation to reproductive health among pregnant women in Kano metropolis.

\section{Literature Review}

\section{Sources of Maternal Health Information Used by Women}

Davies, et al. [24] conducted a study, which aimed at identifying the main maternity information sources used by Somali women living in the Northern city of United Kingdom (UK), the result showed that women sought and used information from several interpersonal sources, which included their mothers, grandmothers and friends, informal sources were perceived as being approachable and providing a means through which further information could be sought, while each information source was also evaluated according to specific criteria. The study was conducted using instructed exploratory focus group and semi structured interviews with Somali women, all the discussions and interviews were audio taped, translated and transcribed in their entirety and then analyzed using a variation of the theme analysis method. Sources of information emerged as sub-theme from the data. O'Keefe et al. [25] conducted a research on the sources of maternal information used by women, the findings of the research revealed that depending on the nature of information need, different sources are been used to get information. Information from the media are usually the most important ones, like the television, which plays an important role in providing health information.

However, other researches by [24] show that print media are the most important sources of getting health information; these include leaflets from health organization, magazine and newspapers for women, medical books and journals. An older research, which was also conducted on the sources of maternal information used by women was done by [26] the findings of the research was contrary to that of [25] because the result revealed that the major sources of health information was from health practitioners and not media sources. Although, the younger clients in the study suggested that the use of information provided by family members should be the major source of information, five hundred and twenty nine (529) 
women were targeted; questionnaires and telephone interviews were used to collect data. Akakandelwa [27] states that the format of information is changing as a result of the impact of technology, access to information can be through internet, computers and mobile phones; our environment is changing by an increasing rate due to information technology. This technology provides improved opportunities for accessing information. The integration of information communication technologies (ICT) in people's life has become today the fastest change in the society.

\section{Accessibility of Maternal Health Information by Women}

The factors that affected the accessibility to maternal health services are unavailability of health facilities in the slums, high cost of maternal health care, low income levels, long queues and waiting times at modern health facilities and the perception that traditional medicines are more healthy and protective for pregnant mother and babies. Also, [27] findings revealed that women had access to maternal information as a result of attending antenatal clinics, which is a maternity service. The maternal information provides women and their families with appropriate information for a healthy pregnancy, safe childbirth, and postnatal recovery, including care of new born baby, exclusive breastfeeding, and assistance with deciding on future pregnancies in order to improve pregnancy outcomes, therefore an effective ANC package depends on the health care providers in an excellent health system with adequate supplies and laboratory support.

\section{Relevance of Maternal Health Information among Women}

O'kereke et al. [28] findings revealed that knowledge of safe pregnancy practice among some of the women in the rural communities is associated with attending antenatal clinic (ANC) or acquiring some level of education, because increasing the knowledge on safe motherhood practice should translate into safer pregnancy outcomes and subsequently lead to lower maternal mortality across the developing world. Also, a review done by American Society for Clinical Nutrition (2000) revealed that three of the main causes of maternal mortality are induced abortion, pueral infection and pregnancy-induced hypertension, knowledge on nutrition is too scanty for programmatic application. Access to obstetric service are vital to help avoid obstructed labour while current programs of universal iron supplementation are unlikely to have much effect on severe anemia. Therefore, there is urgent need to assess the approach to anemia control in pregnant women. American Society for Clinical Nutrition (2000) found that in creating awareness of women's health information, popular magazines and television can be effective. Also, health sciences and public librarians may also assist women in identifying useful information sources by providing guidance in accessing easy-toread magazine articles and authoritative, reliable and relevant web information sites.

\section{Information-Seeking Behaviour of Women Attending Antenatal Care (ANC)}

Kabir, et al. [29] results showed that the knowledge of antenatal care was better among those that utilized antenatal care than those that did not utilize it; also the result showed that health-seeking behaviour is highly distinctive among poor and rich people. 3,549 women were used as the sample size they were interviewed individually. The women that utilized antenatal care, their information-seeking behaviour was good and those that didn't utilize it their own were bad. Therefore informationseeking behaviour can be affected by psychological and personal factors, such as socio-demographic characteristics. Therefore, one can concludes that behaviour is expressed by the use of different information source. Aaronson, et al. [26] conducted a research which examines information-seeking behaviour among pregnant women in a rural region of New Delhi, India, information needs, perceived barriers, knowledge and direct experience were found to be significant predictors of pregnancy related informationseeking. A mixed method approach and a variant of the sequential mixed method was used to collect data, focus group discussion, interview with key informants, and questionnaire was also used, 165 pregnant women attending antenatal clinics were used as the sample size of the study, the need for increasing low-income, rural women's awareness through innovative means were also pointed out in the study. Also, the need for proper counseling, which is an integral component of antenatal, the findings indicate the high confidence level of women in terms of obtaining information, which may delay their information-seeking until complications arise. Their information seeking was bad because it was not in line with the medical regulations of antenatal.

\section{Challenges Faced by Women in Accessing Maternal Health Information}

Jiyane [19] observed that a number of factors create problems when accessing information by any community, but in particular the peri-urban community. Thus, most information access is from the media, such as radio, television, books, magazine, posters, health centers, community groups and clubs. Illiteracy, poverty, unemployment and poor infrastructure, hinder rural community to access information in the peri-urban communities. The findings also reveal that during antenatal care, some women value having access to modern technology. Just as beliefs and practices regarding fertility are culturally patterned, birth itself is a cultural production [20]. Gazali et al. [21] found many challenges women face in order to access health and maternity information. The social and economic status of the country is a contributing factor where poverty levels have increased in the last years. Also, the physical access, cost and lack of ability to use information, that is, illiteracy, which has made it impossible for illiterate women especially having easy access to information relating to women's health and maternity issues. 
Glenton [22] found that the barriers to accessing information include the use of medical terminology by the information source, which the information seeker may not understand. Furthermore, Parker et al. [23] also affirm that low levels of literacy and the understanding of medical information constitute to the barriers of health information seeking.

\section{Empirical Review of Previous Studies}

Brettell, et al. [20] carried out a cross sectional study, between February and October 2011 using 169 healthcare providers (40 doctors, 123 nurses and 6 pharmacists). Questionnaires were used for the study, Data were captured using the Statistical Package for social sciences (SPSS) computer program, and were analyzed using descriptive measures, such as percentage, means, deviation, correlation analysis and inferential statistics. The findings revealed that no specific program target Sexual Reproductive Health or Family Planning, but they are family planning services that desired women can access. There is also no theory being presented in order to support their study. Saleh, et al. [5] used exploratory survey and a cross sectional design, where questionnaires were distributed to pregnant women to know their attitude towards safe motherhood, the population of the study consists of 232 pregnant women who registered in the year 2009 at both government and non-governmental hospitals in Orlu Urban, 240 questionnaires were presented the returned rate was $97 \%$, the result showed that pregnant women had positive attitude towards prenatal or antenatal care, and also the theories used were in line with the findings of the study.

Bandura [30] identified information relating to baby feeding as an information need of pregnant women. This is particularly so as women often express concern over breast feeding and formula feeding. In a related study, [5] identified antenatal and post-natal care, immunizations especially on the six childhood killer diseases, prevention and management of vascular virginal fistula (VVF), and delivery options as the paramount health information required by rural women. In a research conducted by [26] revealed that major sources of information were health care providers and books. Providers topped the list with 1845 points, followed by books (1608 points), friends (925 points), print media (910 points), family (753 points), self (598 points), and audiovisual (380 points). They concluded that multiple channels of acquiring information were used by pregnant women. Saleh, et al. [5] affirmed that health care providers were the highest source of information in their study. Rasheed, et al. [31] also identified family and friends, local herb hawkers, local drug sellers (hawkers) and traditional healers as the most utilized information sources.

Guiglani, et al. (1998) found that women sought information from many sources in the first stage of their research. Towards the later stages, specific information from mid-wives was sought. The authors also outlined various factors influencing HISB, and classified them according to the stages of pregnancy. For example, women in the third trimester were influenced by questions of location, whereas women who had yet to conceive were influence by questions related to conception. Pregnancy, particularly first pregnancy, is a major transition in every woman's life. This is particularly so as a pregnant woman finds herself in a unique and relatively new context, in which she undergoes major physical, psychological, and social transformations. Uloma, et al. [32] state that although pregnancy is exciting, a woman may also experience doubts and uncertainties about her new identity as a potential mother and her life style, which may in turn trigger her to rethink and reconsider a lot of her behaviour, including her nutrition. Since, high quality nutrition is of extra importance during this period, it becomes one of the few logical moments in a woman's life when it is necessary to rethink nutrition habits. Glanz, et al. [33] findings further affirm that women are more interested in nutrition information during pregnancy than before conception.

Rasheed, et al. [31] found that women had an information need for food in pregnancy, rest, exercise importance of antenatal care, antenatal visits, importance of blood examination and immunization in pregnancy among other things. The result showed that many women were well informed about certain aspects of pregnancy, such as dietary requirements, the need of adequate daily exercise and timing of the antenatal visits. The findings indicate that there is need to reactivate health education programs through the local primary health centers as well as the mass media. Uloma, et al. [32] investigate health information needs of pregnant women by identifying the major health problems faced by pregnant women and to the extent to which their information needs are met; descriptive survey research design was used for the study. The population consisted of 50 women, the sampling was enumerative. Structured questionnaire was used for data collection; the data was analyzed using frequency distribution and percentage counts. The result showed that the major problems faced by pregnant were vomiting, lack of appetite, headaches, fear of labour, miscarriages, complication, and hemorrhage. Within the area of channels of information, respondents identified their mothers and the antenatal care givers, followed by their friends as their primary sources of information.

\section{Theoretical Framework}

The study is anchored on Health Belief Model and Wilson Model. The health belief model was first developed in the 1950 by social psychologists Houcbaum, Rosenstock and Kegels working in the U.S Public Health Services. This model holds that the response and utilization of disease prevention programs will be predicted on an individual's knowledge of seriousness of the disease, severity of the disease, information benefit of services, and barriers to accessing such services. Glanz, et al. [33] argued that a wide variety of demographic, social, psychological, and structural might also 
impact people's perceptions and indirectly their health-related behaviours, these factors were later added to connect the various types of perceptions with the predicted health behaviour, it is also a psychological model that attempts to explain and predict health behaviours' by focusing on the attitudes and beliefs of individuals. This model was used due to the fact that is one of the models of behaviour change typically used for studying and promoting the uptake of health services Becker [34]. Therefore Health Belief Model guides and informs health communication and programs as regards to individual response and utilization of health information [35]. Therefore this model was used on the survey of reproductive health information seeking behaviour among pregnant women in some selected hospitals in Kano metropolis.
Wilson Model. The Model was propounded by Wilson in 1997. This model is based on two main propositions. First, that information need is not a primarily need, but a secondary need that arises out of needs of a more basic kind (defined as physiological, cognitive, or affective); and second, that in the effort to discover information to satisfy a need, the enquirer is likely to meet with barriers of different kinds, these barriers are known as intervening variables according to Wilson. The Wilson Model was recently revised in order to direct attention to certain activating mechanism that may influence the decision to satisfy a need for information or search for it (Figure 1) [36]. Two new theoretical ideas were included in the model.

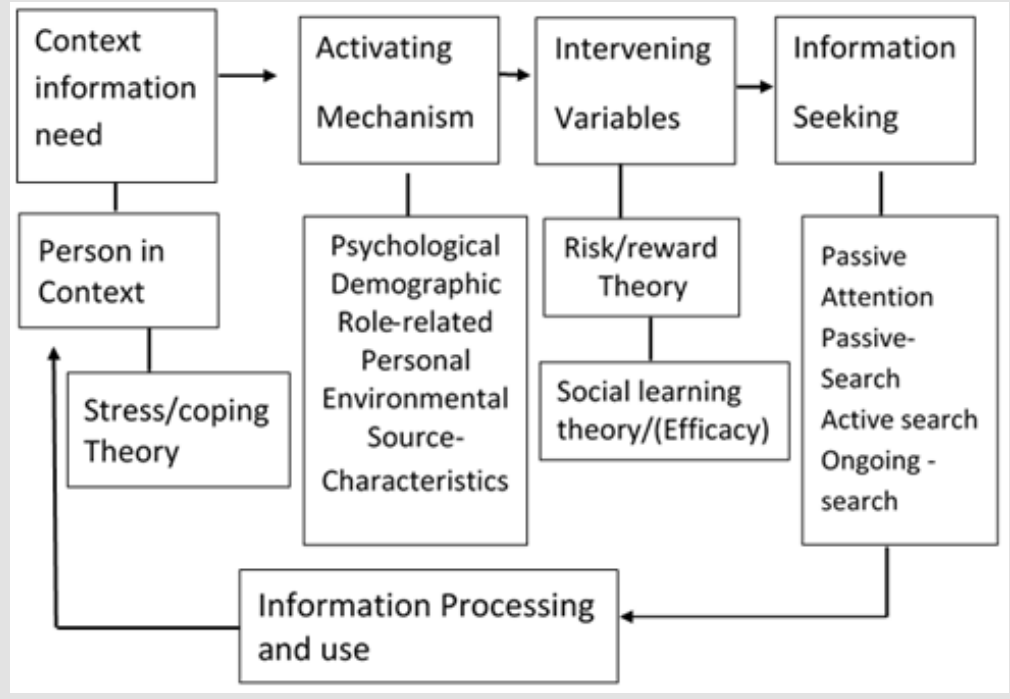

Figure 1.

These were:

1. risk or reward theory, which explains which source of information may be used more than others and

2. social learning theory, which embodies the concept of selfefficacy. Self-efficacy refers to an individual's belief that he or she can successfully execute the behavior required to produce desired outcomes [30]. Thus, Wilson identifies the factors in his model from literature in other fields, including decision making, psychology, innovation, and health communication and consumer research [36].

Therefore, the health belief models is imperative to this study because of its response and utilization of disease prevention programs, which can be predicted on an individual's knowledge of the seriousness of the disease, severity of the disease, information benefit of services, and barriers to accessing such services. Arguably, the theory provides a wide variety of demographic, social, psychological, and structural might, which impact on people's perceptions and indirectly their health-related behaviours, these factors can be added to connect the various types of perceptions with the predicted health behaviour, it also explains and predict health behaviours' by focusing on the attitudes and beliefs of individuals. Similarly, Wilson's Model is also important in activating mechanism that may influence the decision to satisfy, which information that is search for.

\section{Research Method}

This study adopts the positivist approach of data generation and analysis. The positivist or post-positivist assumptions have represented the traditional form of research and these assumptions dwell more on quantitative research than qualitative research. This worldview is sometimes called the "scientific method" or "doing science research". It is also called "empirical science" and "postpositivism". Positivists or Post-positivists hold a deterministic philosophy in which causes (probably) determine the effects or the outcomes. To achieve the success of this design, survey method was employed. Kano State is situated in the Northwestern zone of Nigeria, which is one of the six geopolitical zones of the country. 
It occupies 20131 square kilometers of land mass. The state was created in 1967 and it currently has 44 local government areas, it is made up of mainly Hausa/Fulani who are predominantly Muslims. It has a population of 9383, 6829 and the women constitute $4,539,554$ of the population as revealed by the [37]. Therefore, the study population is 910 pregnant women attending antenatal clinics from 9 selected hospitals in Metropolitan Kano. Two of the hospitals were General Hospitals, one Teaching Hospital, five Primary Health Care Centers, and one private hospital [38]. This number was generated from the patients' daily attendance register of the following hospitals, which also served as a sampling frame for the study. The breakdown of the hospitals is shown in the table below (Table 1).

Table 1.

\begin{tabular}{|c|c|}
\hline Hospitals & Total \\
\hline Standard Hospital & 10 \\
\hline YakasaiZumunta & 20 \\
\hline Nuhu Bamalli Hospital & 150 \\
\hline Kawaji Primary Health Care & 50 \\
\hline Tudun Murtala Hospital & 50 \\
\hline Aminu Kano Teaching Hospital & 100 \\
\hline Murtala Muhammad Specialist Hospital & 300 \\
\hline Muhammad Abdullahi Wase & 200 \\
\hline \multirow{2}{*}{ Tarauni Clinic } & 30 \\
\cline { 2 - 2 } & Total $=910$ \\
\hline
\end{tabular}

Since it was difficult to study the entire pregnant women attending antenatal clinics in Kano State, a representative sample was drawn using Krejcie and Morgan formula [39], the sample size of the population of this study is 269 . Hence, 269 questionnaires were disproportionally shared among the 9 hospitals in Metropolitan Kano. Lack of exhaustive list of the respondents allowed the study to use convenient sampling. Therefore, respondents who attended the antenatal clinics were given questionnaires during and after their antenatal lectures. In order to collect the respondents' opinions about their behaviour towards antenatal care service, a questionnaire with Likert-Scale, Yes or No and Matrix options was adopted [40,41]. The questionnaire was adapted from the [22]. Thus, 269 questionnaires were distributed to the respondents. A well trained research assistant was hired to help in administering the questionnaires to the respondents of the study. He also assisted in translating the questionnaire from English to Hausa language. Of all the 269 questionnaires distributed, 215 questionnaires were returned, 32 were unusable and 22 were not returned. The study employed the use of quantitative approach of data presentation and analysis. Thus, the result was presented using Statistical Package for Social Science (SPSS) software. The research instrument used in the study is questionnaire with open ended questions.

(Table 2) addresses the return rate of the questionnaire and based on the data generated the usable questionnaires were
215 which constitute $79.9 \%$. Unusable questionnaires were 32 representing $11.9 \%$ while not return constitutes 22 with $8.2 \%$. However, considering the negligent number of the unusable questionnaires, the study still found the usable questionnaires significant and representable using Krejcie and Morgan formula (1970). (Table 3) above presented the frequency of the local government of the respondents. The data showed that $54 \%$ ( $\mathrm{n}=$ 116) were from Nassarawa local government, $26.5 \%(n=57)$ were from Kano Municipal while 19.5\% (n= 42) were from Tarauni local government. This indicate that majority of the respondents (54\%) were from Nassarawa local government while the minority (19.5\%) were from Tarauni hospital. (Table 4) above presents the frequency of hospital of the respondents. The result revealed that 19.1\% (n= 41) of the respondents were from Murtala Muhammad Specialists, 16.7\% ( $n=36)$ were from Nuhu Bamalli Hospital, 14.9\% $(n=32)$ were from Nassaraa Hospital, 14\% ( $n=30)$ were from Kawaji Primary Healthcare, 9.3\% ( $n=20)$ were from Aminu Kano Teaching Hospital, 8.4\% ( $\mathrm{n}=18$ ) were from Yakasai Zumunta Hospital, 7.4\% $(n=16)$ were from Tudun Murtala Hospital, 6\% $(n=13)$ were from Standard Hospital while, $4.2 \%$ were from Tarauni Primary Health Care. This showed that majority of the respondents (19.1\%) were from Murtala Muhammad Specialists while the least (4.2\%) were from Tarauni Primary Health Care.

Table 2: Return Rate of the Questionnaire.

\begin{tabular}{|c|c|c|}
\hline & Frequency & Percent \\
\hline Usable Quest. & 215 & 79.9 \\
\hline Unusable Quest. & 32 & 11.9 \\
\hline Not Return & 22 & 8.2 \\
\hline Total & 269 & 100 \\
\hline
\end{tabular}

Table 3: Local Government of the Respondents.

\begin{tabular}{|c|c|c|}
\hline & Frequency & Percent \\
\hline Municipal & 57 & 26.5 \\
\hline Tarauni & 42 & 19.5 \\
\hline Nassarawa & 116 & 54.0 \\
\hline Total & 215 & 100.0 \\
\hline
\end{tabular}

Table 4: Hospital of the Respondents.

\begin{tabular}{|c|c|c|}
\hline & Frequency & Percent \\
\hline Standard Hospital & 13 & 6.0 \\
\hline YakasaiZumunta Hospital & 18 & 8.4 \\
\hline Nuhu Bamalli Hospital & 36 & 16.7 \\
\hline Kawaji Primary Health Care & 30 & 14.0 \\
\hline Aminu Kano Teaching Hospital & 20 & 9.3 \\
\hline Murtala Muhammad Specialist & 41 & 19.1 \\
\hline Nassarawa Hospital & 32 & 14.9 \\
\hline Tarauni Primary Health Care & 9 & 4.2 \\
\hline Total & 215 & 100.0 \\
\hline
\end{tabular}


(Table 5) above presents the frequency of the respondents sources of information for antenatal care. The data revealed that $47.9 \%(n=103)$ of the respondents sourced it from clinic, $26 \%$ $(n=56)$ sourced it from mass media, 13\% $(n=28)$ sourced it from interpersonal contacts while $13 \%(n=28)$ sourced it from all the sourced. This showed that majority of the respondents $(n=$ $47.9 \%)$ sourced their information from clinic. The findings are similar to what [32] found where they identified their mothers, antenatal clinics followed by their friends as their primary sources of information. Among these sources, media sources especially the broadcast media, which plays a significant role in providing reproductive health information. However, it differs from the study carried by [5] which stated that there are basically five sources through which pregnant women satisfy their information needs. These are: government and its agents, elite groups, relatives and friends, market women and Non- Governmental Organization (NGO).

Table 5: Research Question One: What are the sources of reproductive health information used by pregnant women in Kano metropolis?

\begin{tabular}{|c|c|c|}
\hline & Frequency & Percent \\
\hline Clinic & 103 & 47.9 \\
\hline Interpersonal Source & 28 & 13.0 \\
\hline Mass Media & 56 & 26.0 \\
\hline All & 28 & 13.0 \\
\hline Total & 215 & 100.0 \\
\hline
\end{tabular}

(Table 6) above presents the frequency of usefulness of the maternal information to the respondents. The data revealed 72.6 $(n=156)$ of the respondents agreed that the information was very useful, 21.4\% ( $n=46)$ said it was useful, $4.2 \%(n=9)$ said they cannot describe it while $1.9 \%(n=4)$ said it was not useful. This indicate that majority of the respondents agreed that the information they obtained was very relevant. This result concurs with the findings of [28] that the sources of maternal information among pregnant women are useful for the safe delivery of their babies. (Table 7) above presents the frequency of the period the respondents attend antenatal services. The data showed that $48.8 \%(n=105)$ of the respondents attended antenatal services very early, 30.7\% $(n=66)$ attended it early, 19.5\% ( $n=42)$ not early while very few $(n=2)$ attended it very late. This signified that majority of the respondents attended antenatal services very early. The findings of the study is contrary to what [32] found in their study that majority of pregnant women do attend antenatal clinics very late.

Table 6: Research Question Two: How useful were the sources of maternal information to pregnant woman in Kano metropolis?

\begin{tabular}{|c|c|c|}
\hline & Frequency & Percent \\
\hline Very useful & 156 & 72.6 \\
\hline Useful & 46 & 21.4 \\
\hline Not useful & 4 & 1.9 \\
\hline
\end{tabular}

\begin{tabular}{|c|c|c|}
\hline Can't describe & 9 & 4.2 \\
\hline Total & 215 & 100.0 \\
\hline
\end{tabular}

Table 7: Research Question Three: How early do pregnant women attend antenatal clinics?

\begin{tabular}{|c|c|c|}
\hline & Frequency & Percent \\
\hline Very early & 105 & 48.8 \\
\hline Useful & 66 & 30.7 \\
\hline Not useful & 42 & 19.5 \\
\hline Can't describe & 2 & .9 \\
\hline Total & 215 & 100.0 \\
\hline
\end{tabular}

(Table 8) above presents the frequency of the respondents' outcome about their antenatal information seeking behaviour. The data indicate that $71.6 \%(n=154)$ of the respondents believed that their antenatal information seeking behaviour outcome was excellent, $24.7 \%(n=53)$ believed that their outcome was good while $3.7 \%(n=8)$ believed that their outcome was fair. A similar result was obtained in [20] where majority of the outcomes of antenatal information seeking behaviour among pregnant women were very good.

Table 8: Research Question Four: what are the outcomes of antenatal information seeking behaviour among pregnant women in Kano metropolis?

\begin{tabular}{|c|c|c|}
\hline & Frequency & Percent \\
\hline Excellent & 154 & 71.6 \\
\hline Good & 53 & 24.7 \\
\hline Fair & 8 & 3.7 \\
\hline Total & 215 & 100.0 \\
\hline
\end{tabular}

\section{Conclusion}

Reproductive health information seeking behaviour among pregnant women in Kano metropolis play an important role in helping pregnant women understand issues relating to their health and the babies. The findings of the study indicate that the respondents strongly agree that they are satisfied with the information they obtain from antenatal clinics. Apparently, some of the respondents admitted that the information provided to them is very useful and timely too. Therefore, the study articulated that reproductive health practitioners must encourage pregnant women to use other information sources that are readily available which mostly include; family, friends, medical doctors and mass media as well as the internet. Again, reproductive health practitioners should emphasize the importance of attending antenatal clinics on a monthly basis as soon as women become pregnant as this will expose them to a lot of information that will help them with issues pertaining to pregnancy and also avoid complications. Conclusively, the reproductive health information obtained by the pregnant women is very useful and relevant and able to meet their information needs as pregnant women, the information they received made their pregnancy life easier and understandable to 
the changes occurring in their body. Recommendations Based on the findings, the following recommendations are made:

1. Reproductive health practitioners must encourage pregnant women to use other information sources that are readily available, which mostly include family, friends, medical doctors and mass media as well as the internet.

2. Reproductive health practitioners should emphasize the importance of attending antenatal clinics on a monthly basis as soon as women become pregnant as this will expose them to a lot of information that will help them with issues pertaining to pregnancy and also avoid complications.

3. For further studies, a comparative study on reproductive health information attitude between rural and urban pregnant women should be conducted.

\section{References}

1. McQuail D (2005) McQuail's Mass Communication Theory. In: McQuail D (Edt.).). ( $5^{\text {th }}$ Edn.). Sage Publications Ltd, United States.

2. Crozier M, Abraham A, Sommerhalder K, Schulz PJ (2010) Online Health Information Seeking in the Context of the Medical Consultation in Switzerland. Qualitative Health Research 20(8): 1050-1061.

3. Pasinlioglu T (2004) Health education for pregnant women: the role of background characteristics. Patient Education and Counseling 53(1): 101-106.

4. Allen TJ (1996) Information and seeking knowledge work on the World Wide Web. Aslib Proceedings 20: 433-454.

5. Saleh AG, Lassi FI (2011) Information Needs and Information-Seeking Behavior of rural Women in Borno State, Nigeria. Library Philosophy and Practice.

6. Wilson TD (1999) Models in Information behavior Research. Journal of Documentation 55(3): 249-270.

7. (2009) UNICEF. Maternal mortality- A women dies every 5 minutes from child birth in India.

8. Udofia I, Okonofua F (2008) Preventing primary post-partum hemorrhage in unskilled births in Africa. Afri J Reprod Health 12(2): 7-9.

9. Oyedele D (2012) Nigeria ranks high on infant, maternal mortality index.

10. Kistiana S (2009) Socio-economic and demographic determinants of maternal health care utilization in Indonesia. MSc thesis. The Flinders University of Australia, Adelaide.

11. Smith R, Ashford L, Gribble J, Clifton D (2009) Family planning saves lives. In: Smith R, Ashford L, Gribble J, Clifton D (Eds.,)., (4 $4^{\text {th }}$ Edn.,), Population Reference Bureau Report, USA.

12. Barate P, Temmerman M (2009) Why do mothers die? The silence tragedy of maternal mortality. Current Women's Health Reviews 5(4): 230-238.

13. Warren C, Daly P, Toure L, Mongi P (2009) Posnatal care. Opportunities for Africa's newborns: practical data, policy and programmatic support for newborn care in Africa. Partnership for Maternal, Newborn \& Child Health. University of California.

14. (2013) World Bank. Trends in maternal mortality: 1990-2010. Estimates developed by WHO, UNICEF, UNFPA and The World Bank.

15. (2005) Federal Ministry of Health (FMOH). Road map for accelerating the attainment of the millennium development goals related to maternal and newborn health in Nigeria.
16. Metiboba S (2009) Community participation strategies for curbing maternal mortality among the 0 -Kun Yoruba of Ijumu, Nigeria. Pakistan Journal of Social Science 6(4): 224-227.

17. Ezugwu EC, Onah HE, Ezugwu FO, Okafor II (2009) Maternal mortality in a transitional hospital in Enugu, south-east Nigeria. African Journal of Reproductive Health 13(4): 67-72.

18. Onah HE, Ikeako LC, Iloabachine GC (2006) Factors associated with the use of maternity service in Enugu south eastern Nigeria. Social science and medicine 63(7): 1870-1878.

19. Jiyane GV (2002) An Exploratory study of the Information availblility and Utilization by the Rural Women of Melmoth. Kazulu-Natal. University of Zulu land (Dissertation).

20. Brettell CB, Sargent CF (2001) Gender in Cross-Cultural Perspective; Prentice Hall inc. In: Brettell CB, Sargent CF (Eds.))., (6 ${ }^{\text {th }}$ Edn.), India.

21. Gazali WA, Muktar F, Gana MMC (2012) Barriers to utilization and Maternal health care facilities among pregnant and non-pregnant women of child bearing age in Maidugun Metropolitan Council (MMC) and JerebIgas of Bruno state. Continental Journal of Tropical medicine 6(1): 12-22.

22. Glenton C (2000) Developing patient- centered information for back pain suffers. Health Expectations. 5(4): 319-329.

23. Parker RM, Ratzan SC, Lurie N (2003) Health Literacy: A policy challenge for advancing high quality health care. Health Affairs 22(4): 147-153.

24. Davis MM, Bath PA (2002) Interpersonal sources of health and maternity information for Somali women living in the U.K - information seeking and evaluation. Journal of documentation 58(3): 302-318.

25. OKeefe GJ, Boyd HH, Brown MR (1998) Who learns preventive health care information from where: cross-channel and repertoire comparisons. Health Communication 10(1): 25-36.

26. Aaronson LS, Mural CM, Ptoutz SK (1988) Seeking Information: where do pregnant women go? Health Education Quarterly 15(3): 335-345.

27. Akakandelwa A (2000) An assessment of User Education in Academic Libraries: The Case of The University of Zambia (Dissertation). University of Bostwana.

28. Okerere E, Susan Aradeon, Adekunle Akerele, Mustapha Tanko, Ibrahim Yisa, et al. (2013) Knowledge of safe motherhood among Women in Rural Communities in Northern Nigeria: implication for maternal majority reduction. Reproduction Health 10(1): 57.

29. Kabir M, Khan GN (2013) Impact of a Community-based Perinatal and Newborn Preventive care package on perinatal and neonatal mortality in a remote. London.BioMed Central.

30. Bandura (1977) Toward a unifying theory of behavioral change. Psychological Review 85(2): 191-215.

31. Rasheed P, Al Sowielem LS (2003) Health Education Needs for Prenancy: A study among Women attending Primary Health Centers. J family community med 10(1): 31-38.

32. Uloma CO, Adedotun AA (2013) Information-seeking Behavior of Pregnant Women in Selected Hospitals of Ibadan Metropolitan. Ibadan $4(1)$.

33. Glanz K Rimer BK, Lewis FM (2002) Health Behaviour and Health Education Theory, Research and Practice. In: Glanz K Rimer BK, Lewis FM (Eds.).)., (4 ${ }^{\text {th }}$ Edn.,)., San Francisco: Wiley and sons, USA.

34. Becker MH (1974) The Health Belief Model and Personal Health Behavior Health Education Monographs. Journal of sagepub com 2(4): 324-508.

35. Kolawole AO, Uche CI (2005) Perception of Nigerian Women on domestic violence. Evidence from 2003 Nigeria demographic and health survey. African journal of Reproductive Health 9(2): 38-53.

36. Wilson TD (1997) Information behavior: An interdisciplinary perspective. Information Processing \& Management 33(4): 551-572. 
37. (2006) National population commission. Federal Government Extraordinary Gazette.

38. D Rush (2002) American Society for Clinical Nutrition. Nutrition and Maternal Mortality in the Developing World. The American Journal of Clinical Nutrition 72(1): 212-240.

39. Krejcie VR, Morgan D (1970) Educational and psychological measurement.

ISSN: 2574-1241

DOI: $10.26717 /$ BJSTR.2020.30.005006

Hadiza Mustapha Namadi. Biomed J Sci \& Tech Res

(C) This work is licensed under Creative

Submission Link: https://biomedres.us/submit-manuscript.php
40. Polit F, Hungler BP (1985) Essential of nursing research. In: Polit F, Hungler BP (Eds.).)., (4 ${ }^{\text {th }}$ Edn.), JB Lippincott company, United States.

41. Wilson TD (1999) Models in Information behavior Research. Journal of Documentation 55(3): 249-270.

$\begin{array}{ll}\text { BIOMEDICAL } & \text { Assets of Publishing with us } \\ \text { RESEARCHES } & \text { - Global archiving of articles } \\ \text { - Immediate, unrestricted online access } & \text { - Rigorous Peer Review Process } \\ & \text { - Authors Retain Copyrights } \\ & \end{array}$

